\title{
HAGLUND SYNDROME: A CASE REPORT
}

Indira $\mathrm{D}^{1}$, Prakash G², Venkateshwaran K. N³ , Shivashankar M. P4 , Gowrish P5

\section{HOW TO CITE THIS ARTICLE:}

Indira D, Prakash G, Venkateshwaran K. N, Shivashankar M. P, Gowrish P. "Haglund Syndrome: A Case Report". Journal of Evolution of Medical and Dental Sciences 2015; Vol. 4, Issue 53, July 02; Page: 9279-9282,

DOI: $10.14260 /$ jemds/2015/1348

ABSTRACT: Haglund Syndrome is one of the causes of posterior heel pain. It is the inflammation of the tendoachilles at the calcaneal insertional site and the regional soft tissues. It comprises of insertional Achilles tendinopathy, retrocalcaneal \& retroachilles bursitis and posterior calcaneal bony spur. Imaging plays a very important role in the diagnosis as it can be mimicked by several other conditions like isolated retrocalcaneal bursitis, enthesopathies and accessory soleus muscle. Though plain radiograph is the initial modality of investigation, MRI is preferred as it offers superior soft tissue contrast resolution and accurate diagnosis.

KEYWORDS: Haglund, Tendoachilles, Retrocalcaneal bursitis, MRI.

CLINICAL SUMMARY: 40 year old male patient came to orthopedic outpatient department with complaints of right posterior heel pain and associated swelling for past 6 months. He was working as a security guard who used to stand for long hours. There was no history of trauma or any other systemic illness. On examination, there was a tender swelling at the insertional site of Achilles tendon. Lateral radiograph of ankle was done followed by MRI of ankle.

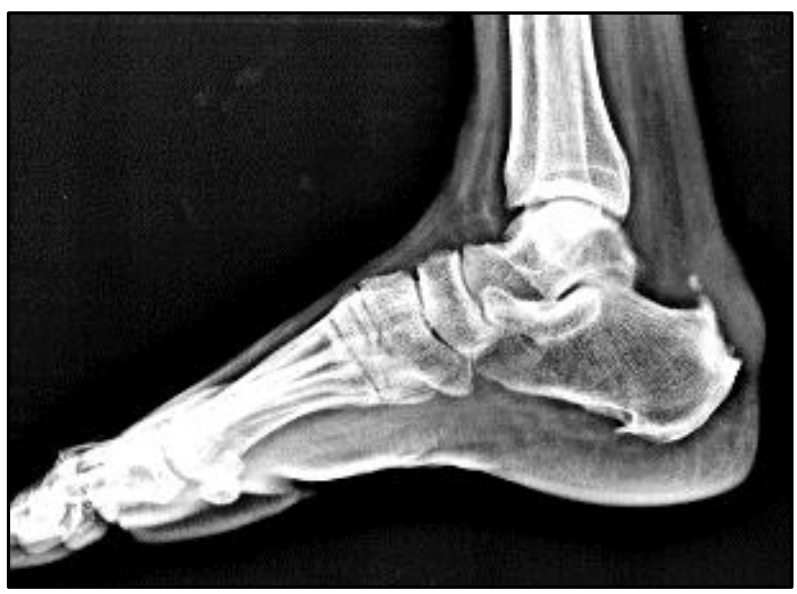

Fig. 1

Fig. 1: Plain Radiograph of ankle - lateral view shows posterior calcaneal spur with calcific focus in the Tendoachilles. Soft tissue swelling is seen at the insertion site of Tendoachilles. Mild obliteration of the Kager's fat pad is seen. Plantar calcaneal spur is also noted. 


\section{CASE REPORT}

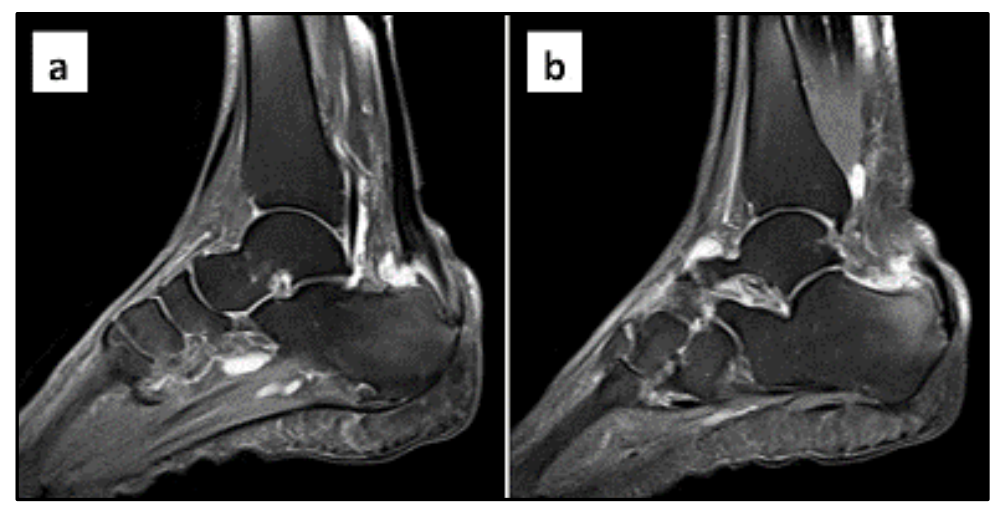

Fig. 2A and 2B

Fig. 2a and 2b: $\quad$ MRI Proton density fat suppressed (PDFS) sequence sagittal sections of ankle (A) shows chronic partial tear of Tendoachilles at the insertion site with associated retrocalcaneal and retroachilles bursitis. (B) Shows marrow edema in the calcaneum at the Tendoachilles insertion site. Inflammation is also seen in Kager's fat pad.

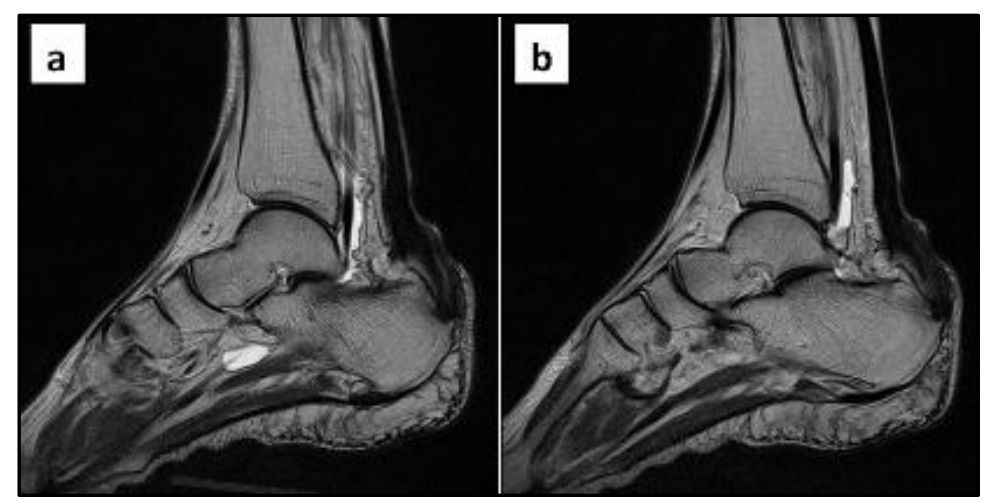

Fig. 3A and 3B

Fig. 3a and 3b: MRI T2WI sagittal sections of ankle shows chronic partial tear of Tendoachilles at the insertion site with associated retrocalcaneal bursitis. Incidentally, fluid is seen around the flexor hallucislongus tendon which is suggestive of flexor hallucislongus tenosynovitis.

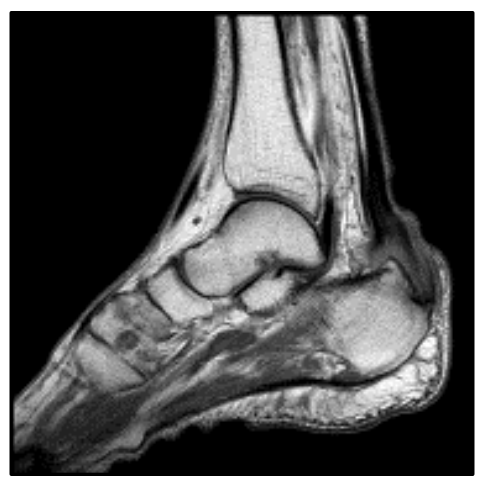

Fig. 4 
Fig. 4: MRI T1WI sagittal section of ankle shows hyperintensity and partial discontinuity of fibers in the Tendoachilles at the insertion site.

DISCUSSION: Haglund syndrome is one of the causes of chronic posterior heel pain. It was first described by Patrick Haglund(1) in 1927. The predisposing factors are wearing tight shoes for long hours, high heels and shoes made up of harder non pliable material. It comprises of a triad which includes insertional Achilles tendinopathy, retrocalcaneal \& retroachilles bursitis and posterior calcaneal bony spur.

Typically patients present with chronic heel pain with associated swelling. On examination, tender swelling is seen at the insertion site of Tendoachilles (TA). There may be decreased range of movement at the ankle joint, especially plantar flexion which causes stretching of the TA.

Plain Radiograph is the initial modality of investigation that shows calcaneal bony spur at the insertion site of TA, thickened TA especially at the insertion site, obliteration of Kager's fat pad and convexity of soft tissues posterior to the TA. When posterior calcaneal spur is subtle causing doubt in diagnosis, objective measurements like posterior calcaneal angle or Fowler's angle,(2) parallel pitch line ${ }^{(3)}$ and ChauveauxLiet angle ${ }^{(4)}$ can aid in the diagnosis.

MRI is the modality of choice especially in ambiguous or clinically equivocal cases as it offers superior soft tissue contrast resolution and bone marrow signal. MRI is more sensitive for making the diagnosis and assessing the severity of the disease.(5) The findings are increased thickness and hyperintensity at the insertion site of TA in T2 and fat supressed sequences. Fluid collection in the retrocalcaneal and retroachilles bursa is best seen in T2 weighted images. Edema is seen in the Kager's fat pad and aroundthe TA insertion site in fat suppressed sequences. Posterior calcaneal bony spur and marrow edema at the TA insertion site is well appreciated in T1 weighted and fat suppressed sequences.

The differential diagnosis includes rheumatoid arthritis, enthesopathies caused by seronegativespondyloarthritis like Reiter's syndrome, Psoriatic arthritis and accessory soleus muscle. Enthesopathies usually involve multiple sites and are associated with mild bone erosion in the bursal surface of calcaneum and osteopenia at the insertion site of tendons unlike Haglund syndrome.

Treatment can be conservative or surgical depending on the severity of symptoms. Conservative management includes change in the foot wear of the patient, oral anti-inflammatory medications and heel elevation. Calcaneal osteotomy or ostectomy and retrocalcaneal decompression are done in selected patients yielding variable results.(6) USG guided intrabursal injection of steroids and local anaesthetic drugs are also used for treatment.(7)

\section{REFERENCES:}

1. Lawrence DA, Rolen MF, Morshed KA et-al. MRI of heel pain. AJR Am J Roentgenol. 2013; 200 (4); 845-55. doi; 10.2214/AJR.12.8824.

2. Pavlov H, Heneghan MA, Hersh A, Goldman AB, Vigorita V. The Haglund syndrome; initial and differential diagnosis. Radiology. 1982;144; 83-8.

3. Pavlov H, Heneghan MA, Hersh A, Goldman AB, Vigorita V. The Haglund syndrome; initial and differential diagnosis. Radiology. 1982; 144(1); 83-88.

4. Singh R, Rohilla R, Siwach RC et-al. Diagnostic significance of radiologic measurements in posterior heel pain. Foot (Edinb). 2008; 18 (2); 91-8. 


\section{CASE REPORT}

5. Robinson P, White LM. Soft tissue and osseous impingement syndromes of the ankle; role of imaging in diagnosis and management. Radiographics. 2002; 22; 1457-71.

6. EHY Hung et al, Haglund Syndrome-a Characteristic Cause of Posterior Heel Pain, J HK CollRadiol. 2009; 11; 183-185.

7. Carolyn M. Sofka, et al, Haglund's Syndrome; Diagnosis and Treatment Using Sonography; HSS Jv.2(1); 2006 Feb PMC2504114.

\section{AUTHORS:}

1. Indira D.

2. Prakash G.

3. Venkateshwaran K. N.

4. Shivashankar M. P.

5. Gowrish P.

\section{PARTICULARS OF CONTRIBUTORS:}

1. Assistant Professor, Department of Radiology, SRM Medical College \& Research Centre.

2. Assistant Professor, Department of Radiology, SRM Medical College \& Research Centre.

3. Assistant Professor, Department of Radiology, SRM Medical College \& Research Centre.

\section{FINANCIAL OR OTHER} COMPETING INTERESTS: None
4. Assistant Professor, Department of Radiology, SRM Medical College \& Research Centre.

5. Resident, Department of Radiology, SRM Medical College \& Research Centre.

\section{NAME ADDRESS EMAIL ID OF THE CORRESPONDING AUTHOR:}

Dr. Indira D,

Door No. 28, Flat F1, Block B, Asian Ecstacy, Bharathy Nagar, $5^{\text {th }}$ Street, Old Perungalathur, Chennai-600063, Tamilnadu, India.

E-mail: srisarv@gmail.com

Date of Submission: 06/06/2015. Date of Peer Review: 08/06/2015. Date of Acceptance: 24/06/2015. Date of Publishing: 02/07/2015. 